\title{
The Performance Of Wireless 802.11 B/G For Data Acquisition Utilization
}

\author{
Fransiskus Xaverius Manggau ${ }^{1 . *}$, Teddy Istanto $^{2}$, Agus priyatno $^{3}$ and Rachmat Rachmat ${ }^{4}$ \\ ${ }^{1}$ Department Of Informatics Engineering, Faculty Of Engineering, Musamus University, Papua - Indonesia \\ ${ }^{2}$ Department Of Informatics Engineering, Faculty Of Engineering, Musamus University, Papua - Indonesia
}

\begin{abstract}
This study aimed to increase the range of the wireless IEEE $802.11 \mathrm{~b} / \mathrm{g}$ by adding the antenna gain, testing the performance of access point with router access point mode of the wireless IEEE $802.11 \mathrm{~b} / \mathrm{g}$, and comparing the performance of access point with router access point mode of the wireless IEEE $802.11 \mathrm{~b} / \mathrm{g}$.This research was conducted in Makassar. The method used was by performing direct performance measurement of end to end node, namely: delay time, throughput and Packet Loss. Wireless access point was placed on the SPN tower (Sekolah Tinggi Kepolisian Negara/College of Police of State) of Batua. Wireless clients were placed at $2.7 \mathrm{~km}, 5.36$ $\mathrm{km}, 8.81 \mathrm{~km}$ and $10.82 \mathrm{~km}$. The results showed that wireless IEEE $802.11 \mathrm{~b} / \mathrm{g}$ can be used for data communications up to $10.82 \mathrm{~km}$ by adding $24 \mathrm{~dB}$ of antenna gain. Wireless with access point mode and router access point mode experienced $100 \%$ of packet loss with 60000 bytes of window size packets' delivery and can handle only 1000 bytes of window size packets. The performance of wireless with access point mode was better than wireless with access point router mode, as follows: For access point packet: $0 \%$ of lost wireless, 8 $\mathrm{ms}$ of delay time, and $1 \mathrm{Mbps}$ of throughput; On the other hand, for router access point packet: $30 \%$ of lost wireless, $26 \mathrm{~ms}$ of delay time, and $0.31 \mathrm{Mbps}$ of throughput. Wireless $802.11 \mathrm{~B} / \mathrm{G}$ can be used as data communication decive for cost-effective data acquisition and has not impact to carbon emission
\end{abstract}

Keywords: Performance; Wireless IEEE $802.11 \mathrm{~B} / \mathrm{G}$.

\section{Introduction}

In 2006, there was a similar flood disaster in Sinjai District. Flash flood disaster occured in a relatively short time in this incident. The torrential downpours in the mountainous areas quickly drowned Sinjai's urban areas and left hundreds dead with huge material losses. With the current environmental conditions, the actual death of humans can be avoided if there is information that can be given quickly from the top of the mountains to the community live around it. Specifically, information about rainfall that is very large and can cause flash floods. However, most regions in Indonesia with topographic models like Sinjai Regency, where there is a highland and low land area with low rainwater absorption, do not have early detection system of flood disaster.

This problem can actually be solved by utilizing data acquisition technology of sensor system integrated with wireless communication system and an information processing software. With this system, data about upstream rainfall can be sent to a monitoring center with a data processing system to decide whether a flood disaster will occur or not. By using wireless technology, the monitoring area becomes more widespread so that the accuracy of the determination of the flood disaster will be better. By using this early detection concept, the threat to community life can be reduced [8].

To realize the early detection system of the disaster, the incorporation of various technologies is required. Ranging from meteorology data sensor system technology such as rainfall, temperature and humidity; wireless communication technology covering various types of technology, ranging from Wireless Personal Area Network (WPAN), Wireless Fidelity (Wi-Fi), Worldwide Interconnection for Microwave Access (WiMAX) and various other technologies and information processing technologies by utilizing various algorithms. It is also necessary to have a reliable information system to process, store and distribute the information to the parties concerned. Thus, this research focuses on data communication using Wi-Fi technology that operates at $2.4 \mathrm{Ghz}$ frequency.

\footnotetext{
* Corresponding author: maryono@pwk.undip.ac.id
} 


\subsection{Wireless Link Budget[3-4]}

The calculation of wireless link budget is the sum and subtraction of signal loss gain and the approximate whether the signal intensity reaching the receiver is high enough for a reliable connection.

\subsubsection{Free Space Path Loss}

When the signal leaves the antenna, the signal will propagate or loose into the air. Antenna will determine how propagation will occur. At $2.4 \mathrm{GHz}$ frequency, it is very important to determine that there is no obstacle in the path between the two antennas. Most likely, there will be degradation of signals propagating in the air if there are obstacles in the path. Trees, buildings, poles, towers, mountains are all examples of obstacles. But most of the attenuation in wireless systems is damping because signals must propagate in the air. A good LOS between the sending antenna and the receiving antenna is essential for both Point to Point and Point to Multipoint installation.

\subsubsection{Fresnel Zone}

The Fresnel Zone Theory is used to quantify Radio Line of Sight. Fresnel Zone has a shape of rugby ball with transmitter \& receiver antenna at the edges, Optical LOS is very easy to understand. LOS radio is more difficult and requires more complex calculations to ensure that the signal is within a safe distance of any obstacles that it will pass through. In the Fresnel zone area, there should be no signal interference. Some people use the consensus that if $60 \%$ of the Fresnel Zone is added three meters free from obstacles, then the LOS Radio is good. Some adopt that there must be nothing hinder in $80 \%$ of Fresnel Zone to get good LOS Radio. If there are obstacles in the Fresnel Zone area, then the performance system will be disrupted.

To know the minimum height required to make the antenna work properly, it is necessary to calculate the required fresnell zone clerence (FZC). The formula used to calculate FZC is:

\begin{tabular}{|c|c|c|}
\hline \multirow{2}{*}{\multicolumn{2}{|c|}{ Where : }} & $F Z C=17,32$ \\
\hline & & 14.5 \\
\hline FZC & $=$ & $\begin{array}{l}\text { Fresnell Zone Clerence } \\
\text { (meter) }\end{array}$ \\
\hline d & $=$ & $\begin{array}{l}\text { the distance between access } \\
\text { point and end-user }(\mathrm{km})\end{array}$ \\
\hline$f$ & $=$ & frequency $(\mathrm{GHz})$ \\
\hline
\end{tabular}

Frequently used field conditions are multiplying $80 \%$ of the FZC gained.

Radiation emitted by an antenna is expressed in units of $\mathrm{dBm}$ with an EIRP (Effective Isoptropic Radiated Power) size. The formula used is as follows:

$$
\begin{gathered}
\text { EIRP }(\mathrm{dBm})=\text { TX Power }-T X \text { Cable Loss } \\
+T X \text { Antena Gain }
\end{gathered}
$$

In order to achieve maximum results, the calculation of lost signal as far as distance between access point with end-user is done. For distances is in miles, frequencies is in $\mathrm{MHz}$. The formula is:

$$
L=20 \log (d)+20 \log (f)+36,6
$$

for distance is in $\mathrm{km}$, frequency is in $\mathrm{MHz}$

$$
L=20 \log (d)+20 \log (f)+32,4
$$

\subsubsection{RSL (Receive Signal Level)}

RSL is the received signal level at the receiver and its value must be greater than the sensitivity of the receiving device (RSL $\geq$ Rth). The sensitivity of the receiving device is the sensitivity of a device on the receiving side of the threshold size. The RSL value can be calculated by the following equation:

$$
R S L=E I R P-\text { Lpropagation }+G R X-L R X
$$

where :

EIRP

Lpropagation $=$ wave losses during propagation

Effective Isotropic Radiated Power $(\mathrm{dBm})$

$(\mathrm{dB})$

GRX $=$ antenna gain receiver $(\mathrm{dB})$

LRX $=$ receiver channel losses $(\mathrm{dB})$

Prevention of absorption and loss of radio waves transmitted can be done by determining the margin limit acceptable to end-users. This margin is known as the System Operating Margin (SOM), SOM is calculated by this equation:

$$
S O M=R x \text { Signallevel-Rxsensitivity }
$$

Unit used:

$$
\begin{array}{ll}
\text { System Operating Margin } & =\mathrm{dB} \\
\text { Rx Signal Level } & =\mathrm{dBm} \\
\text { Rx Sensistivity } & =\mathrm{dBm}
\end{array}
$$

SOM calculations uses three parameters. It requires equations consisting of frequencies used to communicate which generally transmit power, normally by $30-100 \mathrm{~mW}$ (15-20dBm). IEEE 802.11 generally has Rx sensitivity of -80 to $-85 \mathrm{dBm}$. On the user side using a parabolic antenna has a gain of 19-24 dB. The missing signal on the coaxial cable generally has a value between 2 to 2 $\mathrm{dB}$. Thus, to be able to communicate well, the margin limit should be more than $15 \mathrm{db}$.

\subsection{Frequency Usage Rules}

All frequencies used in Indonesia must be licensed by the government, in this case, it is set by the Directorate General of Post \& Telecommunications (DITJEN POSTEL) under the Ministry of Communication \& Information (DEPKOMINFO). Especially 
for the operating frequency that is in the $2.4 \mathrm{GHz}$ band, since January 5, 2005, after signing the Ministerial Decree no. $2 / 2005$ on Wireless Internet at $2.4 \mathrm{GHz}$ by Hatta Rajasa. KEPMEN (Ministrial Decree) of 2/2005, then in principle, $2.4 \mathrm{GHz}$ free frequency is used with the terms, among others,

1. Maximum transmit power is $100 \mathrm{~mW}$

2. EIRP maximum is $36 \mathrm{dBm}$

3. All equipment used is certified.

\subsection{Measurement technique $[2,6,7]$}

PING is one of the programs used to check communication between computers in a network through $\mathrm{TCP} / \mathrm{IP}$ protocol. PING will send Internet Control Message Protocol (ICMP) Echo Request messages to the destination/target computer's ip address and request a response from that computer.

If the target computer responds, then the computer provides information such as the example of PING report you provide: bytes $=32$ time $=30 \mathrm{~ms}$ TTL $=123$. Bytes shows the requested packet request. Time shows the value of "round trip delay" (also called delay or latency) which indicates the time it takes for the packet you send to reach the target computer. This value is calculated by dividing the two time difference of PING packet starts to be sent with the response time of PING packet received. While TTL is the value of "Time-ToLive" is used to prevent the circular routing on a network. By reducing the initial TTL value of 128 with the final TTL value, the number of hops traveled from the original computer to the target computer can be calculated. Every time a PING packet passes through an ip address, its TTL value will be reduced by one. So if TTL reaches zero, PING packet will be discarded/dropped and PING results show: TTL expired in transit. The uses of PING include the following:

1. Knowing the status of up/down of computers in the network.

2. Monitoring the availability of computer status in the network.

3. PING can be used as a monitoring tool of computer availability in the network which is one of the network quality indicator that is by doing PING periodically on the target computer. The smaller the downtime, the better the network quality.

4. Knowing the responsiveness of a network communication

5. The amount of delay or latency value reported by PING becomes an indication of how responsive communication occurs with the intended computer. The greater the delay value indicates the slower the response is given..

6. Calculating Throughput

\section{Research Method}

\subsection{Research Scenario}

In this research, there are several scenarios in performing end-to-end wireless performance measurement, namely:

1. Wireless Point to Point Scenario with a distance of $100 \mathrm{~m}, 200 \mathrm{~m}$ and $300 \mathrm{~m}$.

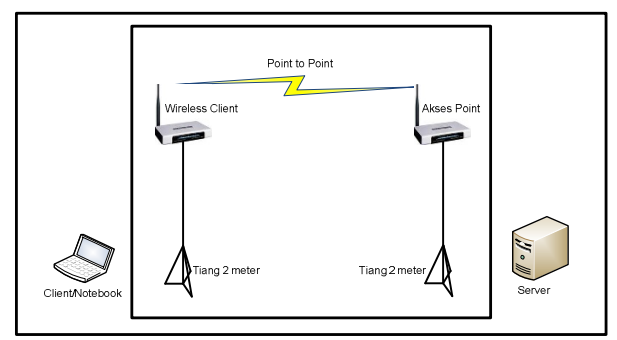

Fig. 3. Wireless Point to Point

2. Wireles Point to Point with repeaters with a distance of $200 \mathrm{~m}, 300 \mathrm{~m}, 400 \mathrm{~m}, 500 \mathrm{~m}, 600 \mathrm{~m}$ and $700 \mathrm{~m}$

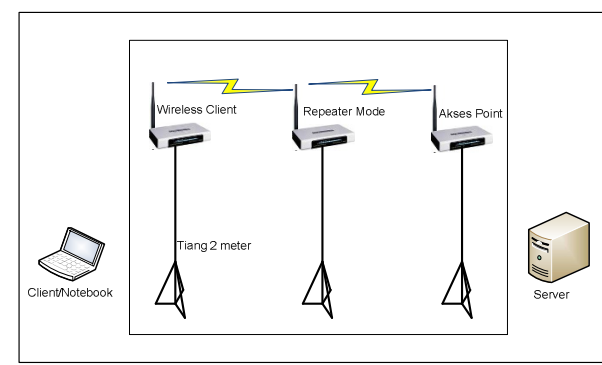

Fig. 4. Wireles Point to Point dengan repeater

3. Wireles Point to Point with external antenna with a distance of $2.75 \mathrm{~km}, 5.36 \mathrm{~km}, 8.81 \mathrm{~km}, 10.82 \mathrm{~km}$.

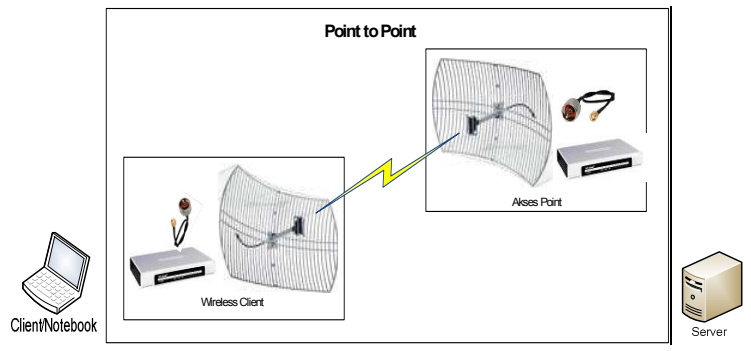

Fig. 5. Wireles Point to Point with external antenna

\subsection{Wireless Network Performance}

The scenarios to be tested on the $802.11 \mathrm{~b} / \mathrm{g}$ wireless performance consist of delay time, throughput and packet loss. Delay time is the time it takes to send a number of packets from source to destination/target. Throuhgput is the number of bits that can be passed in units of time. The Packet Loss is the number of lost packets in the delivery or the number of undelivered packets. This performance can be found using Ping tools. 


\section{Result and Discussion}

In this study, google earth software is used to measure the distance of placement between Wireless access point and wireless client. The wireless placement nodes are firstly surveyed and then viewed by using google earth. Then, the distance is mesured in miles. Figure 6 . Distance map of $2.75 \mathrm{~km}$ is a map of location and distance of scenario III measurement. In this research, Wireless access point is placed at Radio Communication Station of College of Police of State (SPN) of Batua, has a height of $65 \mathrm{~m}$, and wireless client with distance of $2.75 \mathrm{~km}$ that is at Faculty of Engineering of UNHAS in 4th floor.

Wireless client with a distance of $5.36 \mathrm{~km}$ from wireless access point is placed in Academy of Nursing os Nusantara, wireless client is placed on 4th floor so that Optical loss can be seen. Wireless client with a distance of $8.81 \mathrm{~km}$ is located at the Living Environment Office of Makassar, with tower height of $24 \mathrm{~m}$. Wireless client with a distance of $10.82 \mathrm{~km}$ is placed on a Blackberry billboard located at intersection 4 of Airport Mandai with a height of 16 meters from the ground.

\subsection{Fresnel Zone}

To know whether the communication between Wireless access point and wireless client can communicate, then calculation of Freznel Zone is performed (chapter II), that is as follows.

Then the antenna height required to meet Optical Loss and FZC $60 \%$ is like table 1

Antenna Height $=$ Obstacle Height + FZC
Obstacle Height $=15 \mathrm{~m}$

Table 1. FZC Table

\begin{tabular}{|c|c|c|c|}
\hline NO. & $\begin{array}{c}\text { DISTANCE } \\
(\mathrm{km})\end{array}$ & $\begin{array}{c}\text { 60\% FRESNEL } \\
\text { ZONE }\end{array}$ & $\begin{array}{c}\text { ANTENNA } \\
\text { HEIGHT }\end{array}$ \\
\hline 1 & 2.75 & 5.52 & 20.52 \\
\hline 2 & 5.36 & 7.71 & 22.71 \\
\hline 3 & 8.81 & 9.88 & 24.88 \\
\hline 4 & 10.80 & 10.94 & 25.94 \\
\hline
\end{tabular}

\subsection{Link Budget}

Calculation of Link budget is done to know the magnitude of power reception on the wireless client side so it can be known whether the Wireless access point's and wireless client's device can occur/operate or not, the following is table specification of Wireless access point's and wireless client's device used:

Wireless $802.11 \mathrm{~b} / \mathrm{g}$ Device Specification

\begin{tabular}{|c|c|c|}
\hline 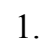 & Radio Power & $=20$ \\
\hline & Antenna Gain & $=24$ \\
\hline & Loss Wire & $=2.0$ \\
\hline & Receiver Sensitivity & $=-74$ \\
\hline & Frequency & $=2437$ \\
\hline
\end{tabular}

Table 2 Link budget table

\begin{tabular}{|c|c|c|c|c|}
\hline NO & DISTANCE $(\mathrm{KM})$ & FSL & RSL & SOM \\
\hline 1. & 2.75 & 108.97 & -44.97 & 29.03 \\
\hline 2. & 5.36 & 114.77 & -48.97 & 25.03 \\
\hline 3. & 8.81 & 119.09 & -55.09 & 18.91 \\
\hline 4. & 10.80 & 120.86 & -56.86 & 17.14 \\
\hline
\end{tabular}

\subsection{Ping Measurement Result}

To find out the lost and RTT packets, it is done by sending data of 60,000 bytes to the server, Based on the overall scenario that has been designed, the following is the measurement of signal reception, packet loss and RTT with two modes, namely access point mode and router access point mode.

From the ping measurement results, throughput can be calculated so that throughput comparison chart between access point mode and router access point mode can be made.

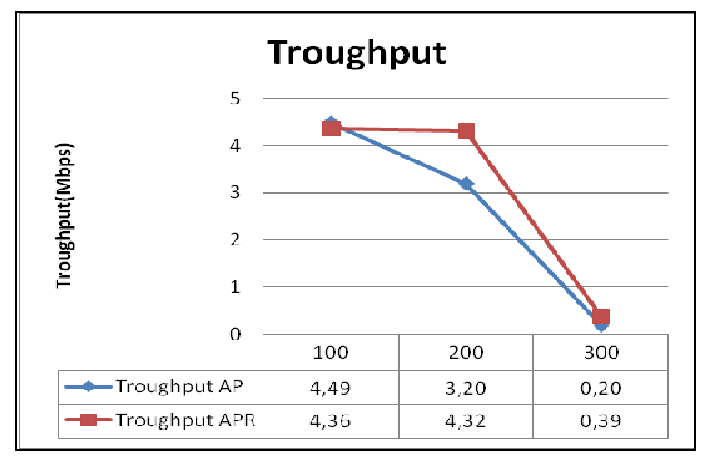

Fig. 8. Throughput skenario I Chart

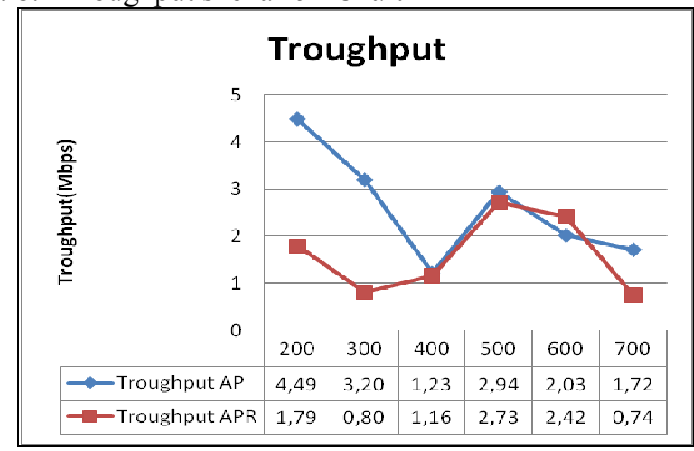

Fig. 9. Throughput skenario II Chart

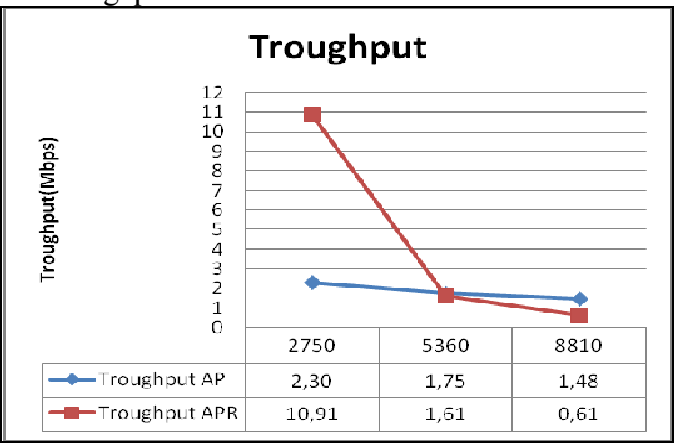

Fig. 10. Throughput skenario III Chart 
Figure 11 is an RTT chart for access point mode and router access point mode. Measurement was done by using Ping, packet size was 60000 bytes with number of iteration was 10 .

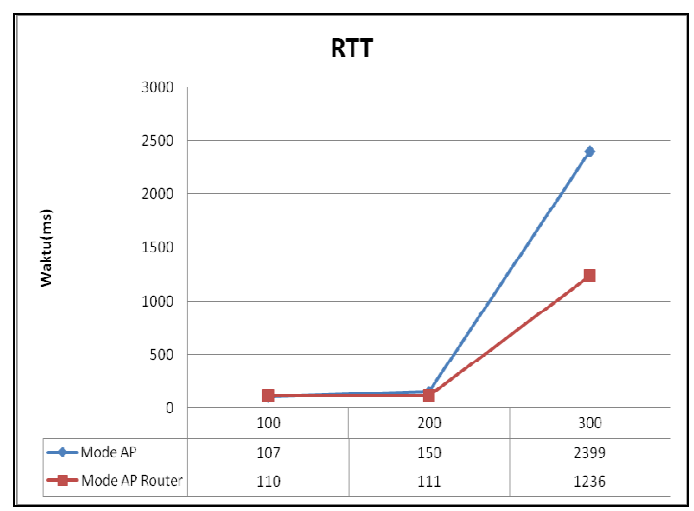

Fig. 11. RTT skenario I Chart

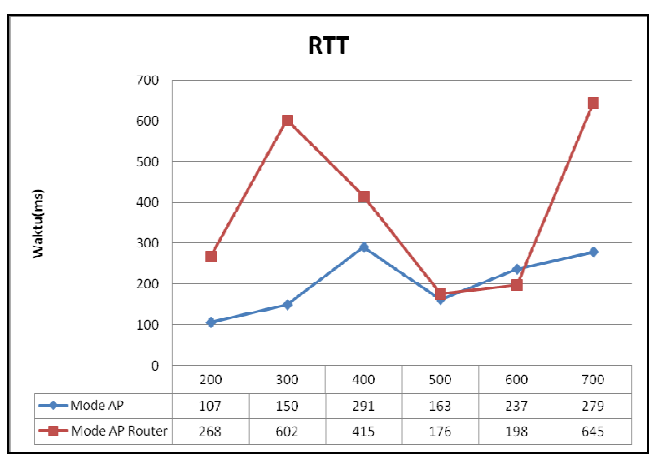

Fig. 12. RTT skenario II Chart

Performance measurement at the distance of 10.82 $\mathrm{km}$ with 60000 bytes of window size packet experienced $100 \%$ of packet loss. Therefore, it was done by delivery of 1000 bytes of window size packet. These measurements used different wireless IEEE $802.11 \mathrm{~b} / \mathrm{g}$ vendors on the client side (komodo bali and Tp-link) with the same device specification that had a power output of $20 \mathrm{dbm}$ or $100 \mathrm{mw}$.

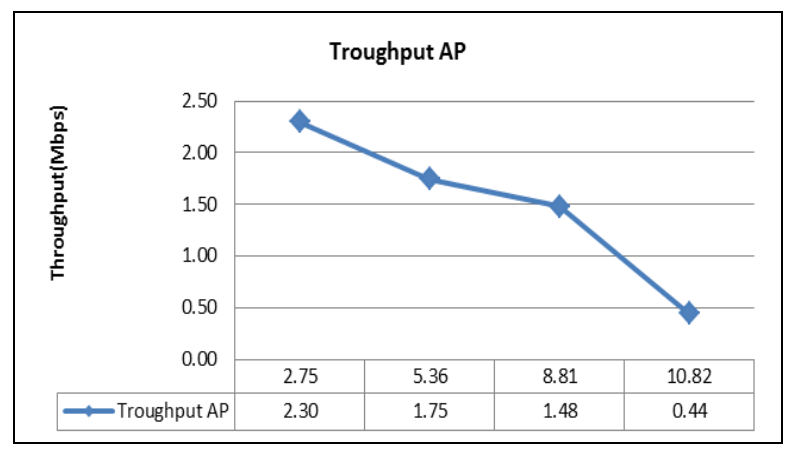

Fig. 13. Throughput Chart

\section{Conclusion}

From the research on the performance of Wireless IEEE $802.11 \mathrm{~b} / \mathrm{g}$ that has been conducted here, it can be concluded that:

1. Wireless IEEE $802.11 \mathrm{~b} / \mathrm{g}$ is designated as an indoor wireless device that can be functioned as an outdoor wireless device with a distance of up to $10.82 \mathrm{~km}$.

2. The farther the distance between wireless access point and wireless client will result in decreased wireless performance of both access point mode and router access point mode so that the less power received by wireless client, RTT increases, delay increases and throughput decreases.

3. The performance of wireless with access point mode is better than wireless with access point router mode, as follows: For access point packet: $0 \%$ of lost wireless, $8 \mathrm{~ms}$ of delay time, and $1 \mathrm{Mbps}$ of throughput; On the other hand, for router access point packet: $30 \%$ of lost wireless, $26 \mathrm{~ms}$ of delay time, and $0.31 \mathrm{Mbps}$ of throughput.

\section{References}

1. Abas Ali Pangera. 2008. Menjadi Administrator Jaringan Nirkabel. Andi : Yogyakarta

2. D. Mills. June 1995. Improved Algorithms for Sincronisation Computer Network Clock. IEEE Transaction Networks, Vol 3 hal. 245-254

3. Jim Geier, 2006. Wireless Network First-Step. Andy Yogyakarta

4. Raharjo, H. R. 2002. IEEE 802.11 Sebagai standar Teknologi Jaringan Komputer Nirkabel. Salatiga. Tugas Akhir. Fakultas Teknik Universitas Kristen Satya Wacana.

5. Regis, J. 2001. Wireless Broadband Handbook, McGraw-Hill. United States Of America

6. Wowok, 2008. Antena wireless untuk rakyat. Andi : Yogyakarta

7. Stallings, William. 2002. Wireless communications and Networking. Prentice-Hall: New Jersey.

8. Zahir Zainuddin, 2008. Proposal Penelitian:Pengembangan Prototipe Sistem Jaringan Sensor Hidrometeorologi Nirkabel dan Model Hidrodinamik Berbasis GIS untuk Peringatan dini Bencana Banjir.Universitas Hasanuddin: Makassar. 